\title{
Knowledge and practice of menstrual hygiene among adolescent school girls in Umunna, Imo State, Southeast Nigeria: implications for parents, healthcare providers and policy makers
}

\author{
Chika. O. Duru', Eugene M. Ikeanyi ${ }^{2 *}$, Irene Merenu ${ }^{3}$
}

\author{
${ }^{1}$ Department of Paediatrics and Child health, ${ }^{2}$ Department of Obstetrics and Gynaecology, Niger Delta University \\ Teaching Hospital, Okolobiri Bayelsa State, Nigeria \\ ${ }^{3}$ Department of Community Medicine, Imo State University Teaching Hospital Orlu, Imo State, Nigeria
}

\author{
Received: 15 October 2020 \\ Revised: 04 December 2020 \\ Accepted: 04 January 2021 \\ *Correspondence: \\ Dr. Eugene M. Ikeanyi, \\ E-mail: abuchikeanyi@yahoo.com
}

Copyright: (C) the author(s), publisher and licensee Medip Academy. This is an open-access article distributed under the terms of the Creative Commons Attribution Non-Commercial License, which permits unrestricted non-commercial use, distribution, and reproduction in any medium, provided the original work is properly cited.

\begin{abstract}
Background: Menstrual hygiene management is critical in the life of the woman. For optimal attendance and participation in school activities, future reproductive and sexual health; quality menstrual hygiene practice is crucial. The objective of this study was designed to assess the knowledge, practice and challenges of menstrual hygiene management among the adolescents

Methods: A cross-sectional study was conducted on a community secondary school girls from $1^{\text {st }}$ May to $30^{\text {th }}$ June 2016. Data was collected with a semi-structured pre-tested questionnaire and analyzed with statistical software as appropriate.

Results: A total of $416(97.4 \%)$ of the respondents were analyzed. Their mean chronological age and age at menarche were $15 \pm 2.1$ years and $12.9 \pm 0.7$ years respectively. Most $(77.9 \%)$ of the respondents had premenarchal menstrual hygiene knowledge and mothers $(68.8 \%)$ were the main source of information. Sanitary pad $(56.3 \%)$ and cloth $(31.2 \%)$ were the most commonly used absorbents. Sanitary pad use was higher in respondents whose mothers had higher level education $(\mathrm{RR}=6.3, \mathrm{p}<0.001)$. Most of the respondents changed absorbent twice or less daily $(77.4 \%)$, bathed at least twice $(77.4 \%)$, washed vulvoperineal region with soap and water $(50.2 \%)$ and wiped perineum front to back (72.8\%). Burning (51.9\%) and refuse dump (26.0\%) were the main disposal methods and $48.1 \%$ washed hands before and after changing menstrual absorbent materials. Main menstrual disturbances were abdominal pain (37.7\%) and malaise (18.5\%) and main intervention was medication from patent medicine store (47.2\%). Menstruation-related school absenteeism was $30.8 \%$.

Conclusions: There was poor premenarchal menstrual awareness and inappropriate menstrual hygiene practices among adolescent schoolgirls.
\end{abstract}

Keywords: Adolescent, Menarche, Menstruation, Menstrual hygiene management, School girls

\section{INTRODUCTION}

Menarche is the first natural menstruation that marks the onset of ovulation and signals reproductive maturity in the girl child. Its timing, pattern and associated physical, social and emotional influences vary from one girl child to another. It may indicate underlying pathology if it occurs too early; under the age of ten or absent after the age sixteen years. Menstruation is strictly and inherently feminine and regular menstruation largely indicates quality health and fertility. One of its early challenges is how to appropriately manage the menstrual hygiene as menstrual hygiene management (MHM) has reproductive and sexual health implications. Menstrual hygiene 
management is jointly defined by World Health Organization (WHO), UNICEF and JMP as 'Women and adolescent girls using clean menstrual management materials to absorb or collect menstrual blood that can be changed in privacy as often as necessary for the duration of the menstruation period, using soap and water for washing the body as required and having access to facilities to dispose of used menstrual management materials'. In addition, 'they understand the basic facts linked to the menstrual cycle and how to manage it with dignity and without discomfort or fear' ${ }^{1-2}$ In addition, for an effective MHM, the taboos and the negative societal beliefs relating to menstruation should be addressed. ${ }^{2-3}$ In the recent times there has been increasing global attention to management of menstrual hygiene..$^{2,4-5}$

Menstruation despites its importance and significance, is often associated with dirtiness, bloody and malodorousness with subsequent feeling of inferiority and devaluation by the woman. ${ }^{2,6}$ These are some of the genesis of menstrual taboos and gender discrimination.

In some societies menstruating women are considered impure and avoided by men as filthy and grubby, which behavior leads to low self-esteem and feeling of dirtiness and shame by the women anytime in menstruation. ${ }^{2,7}$ Still in some other settings it is taboo to freely discuss menstruation. ${ }^{2,8}$ For instance a study on schoolgirls in India reported that less than two in five of the participant girls were aware of menstruation premenarchal. ${ }^{2,9}$ Most of the girls in another report in Zambia learnt of menstruation after menarche and did not know its physiological basis. ${ }^{10}$ A systematic review reported that only $48 \%$ the girls in 88 studies amongs 138 studies were informed of MHM prior to menarche. ${ }^{11}$

For an effective management of menstrual hygiene, there should be accessible quality water, sanitation and hygiene (WASH) services. It is in the literature that as many as 663 million and 2.4 billion people respectively lack access to safe water and adequate sanitation. ${ }^{2,12}$

Different kinds of substances have been used by women to absorb menstrual blood in most cases in low and middle income societies. These include paper, bark, mud, sand, cloth and other non-conventional absorbent materials. ${ }^{2,6,10}$

For regular school attendance, physical participation in school activities and education, provision of quality water, sanitation and hygiene (WASH) facilities for MHM are crucial. Others are access to absorbent sanitary pads, quality toilet and washing facilities, adequate privacy and avoidance of the stigma from public disgrace from open menstrual hygiene accidents. Similarly cultural and religious restrictions on women by menstruation including the stigma of the ritual of uncleanness during menstruation. This will ensure comfort, self-confidence and regular school attendance to reduce gender disparities in education, health, sociopolitical and economic participation. ${ }^{10,13}$

Adolescence is a critical period in human hood especially in the female human. It spans from the first 10 to 19 years and marks the period of transition from the stage of sexual, reproductive psychological and socioeconomic immature and dependent childhood to that of mature and independent adulthood. This is the period in life when most of the adolescents are undergoing their secondary school education. This informed the conduct of this study to investigate the level of menstrual awareness and hygiene practices by this transitional group to recommend steps to maintain healthy menstrual hygiene practices.

\section{METHODS}

This was a descriptive cross sectional study conducted in Niger Delta University Teaching Hospital (NDUTH), a tertiary health facility domicile at Okolobiri, Bayelsa State, South-south geopolitical region of Nigeria. Bayelsa state is one of the oil rich states of Niger Delta region of Nigeria. It is bounded to the north by Delta State, to the west by Rivers State and to the East and South by Atlantic Ocean. Data was collected from $1^{\text {st }}$ May to $30^{\text {th }}$ June 2016 on secondary school girls aged 11-19 years in purposively chosen secondary schools in Umuna in Orlu L.G.A of Imo State in South-Eastern Nigeria. Orlu is the second largest city after Owerri the state capital in Imo state, South-eastern Nigeria, with an estimated population of 420,000 consisting mainly of farmers, traders and civil servants. Orlu is located between latitude $5^{0} 43^{\prime} \mathrm{N}$ to $5^{0} 51^{\prime} \mathrm{N}$ and longitude $7^{0} 00 \mathrm{E}$ to $7009^{\prime} \mathrm{E}$. Orlu L.G.A is made up of many communities and is bounded by Nkwere, Isu, Njaba, Orsu, and Ideato-north L.G.A respectively.

Umuna is made up of three electoral wards namely Ezedike, Ebenese, and Uzubi. According to the 2006 Nigerian national population census, Umuna has a total population of 53,852 of adults 18 years and above (27,032 females and 26,820 males). Most of them are Christians of various denominations; the population is predominantly Igbo.

The Secondary Schools in Umuna Comprises of Urban Secondary School Umuna, Community Secondary School Umuna, St. Joseph Secondary School Umuna, City Technical School Umuna and Sharma Modern Secondary School Umuna. The above named schools are mixed secondary school (i.e., boys and girls). The students comprises of indigenes of Umuna and non indigenes.

Data were collected on the menstrual hygiene management (MHM) practices with the aid of semistructured pretested interviewer -assisted questionnaire. The questionnaire was structured into two sections. Section A contained the independent variables (sociodemographic characteristics); age in years, class 
level (junior secondary school (JSS 1-3) to senior secondary school (SSS 1-3), religion, ethnicity and maternal educational level. Section B contained the dependent variables on MHM. These are knowledge of menstruation, menstrual hygiene materials and the practices. Awareness was based on premenarchal information and correct practices about menstruation. Only female students between the ages of 11 and 19 years and girls who have commenced menstruation were recruited for the study after informed verbal consent. Those who declined consent and the ones absent from school during recruitment were excluded from the study. The sample size was determined according to the formula by Cochrane GW ${ }^{14}$ and prevalence rate of $48 \%$ as below. ${ }^{11,14}$

$$
\mathrm{n}=\mathrm{z}^{2} \mathrm{pq} / \mathrm{d}^{2}
$$

Where $\mathrm{P}=$ Maximum known prevalence of premenarchal awareness in literature,

$\mathrm{q}=1-\mathrm{p}$ (complement of $\mathrm{p}$ ).

$\mathrm{d}=$ Allowable error margin of estimate (precision) $=$ 0.05 ,

$\mathrm{Z}=$ this is $\mathrm{Z}$ statistic for $95 \%$ confidence level (value for selected alpha level $\alpha=0.05$ which is conventionally 1.96 . $\mathrm{n}=$ sample of adolescent secondary schoolgirls i.e. sample size $=384$

To further increase the power of the study the sample size was increased to 427 to allow for attritions. The sample was drawn using the stratified sampling technique.

The data was fed into Epi Info Version 3.5.1 designed by Center for disease control and prevention (CDC) in Atlanta Georgia, USA, released August 2008 and INSTAT statistical software.. The univariate data analysis of categorical variables was in frequency and percentage while parametric data was into frequency, mean and standard deviation. Test of statistical association was done using the Fisher's exact test for bivariate statistical analysis as appropriate using 2 × 2 contingency tables and presented as relative risk (RR) and significance level was set at p-value of 0.05 or $95 \%$ Confidence Interval exclusion of the nullity of one.

Permission was obtained from ethics committee of the department of community medicine, Imo State University Teaching Hospital Orlu, while permission for the study was obtained from the head/principal of the selected secondary schools, prior to the interview.

\section{RESULTS}

A total of $416 / 427(97.4 \%)$ of the questionnaires were satisfactorily filled, included in the study and analyzed while $11(2.6 \%)$ were attritions.

Table 1 shows the sociodemographic characteristics of the respondents. The mean chronological age of the respondents was $15 \pm 2.1$ years, ranged from 11 years to 19 years. The modal age group was $14-16$ years constituting $50.4 \%$ of the respondents. Most of the respondents were Igbo (97.6\%), Christians $(98.8 \%)$ and in the senior secondary school class $(70.7 \%)$.Over three of five $(64.9 \%)$ of the respondents' mothers were of lower educational level.

Table 1: Characteristics of the respondents $(n=416)$.

\begin{tabular}{|llll|}
\hline Characteristics & Variables & Frequency & Percent \\
\hline \multirow{2}{*}{$\begin{array}{l}\text { Chronological } \\
\text { age (years) }\end{array}$} & $11-13$ & 103 & 24.8 \\
\cline { 2 - 4 } & $14-16$ & 210 & 50.4 \\
\cline { 2 - 4 } & $17-19$ & 103 & 24.8 \\
\hline $\begin{array}{l}\text { Junior } \\
\text { (JSS1-3) }\end{array}$ & 122 & 29.3 \\
\cline { 2 - 4 } & $\begin{array}{l}\text { Senior } \\
\text { (SS1-3) }\end{array}$ & 294 & 70.7 \\
\hline Religion & Christianity & 411 & 98.8 \\
\cline { 2 - 4 } $\begin{array}{l}\text { Islam } \\
\text { Family }\end{array}$ & First & 5 & 1.2 \\
\cline { 2 - 4 } Position & $\geq$ Second & 188 & 54.8 \\
\hline Ethnicity & Igbo & 406 & 45.2 \\
\hline Others & 10 & 97.6 \\
\hline $\begin{array}{l}\text { Mother's } \\
\text { Education }\end{array}$ & $>2^{\circ}$ & 270 & 64.9 \\
\cline { 2 - 4 } & $>2^{\circ}$ & 146 & 35.1 \\
\hline
\end{tabular}

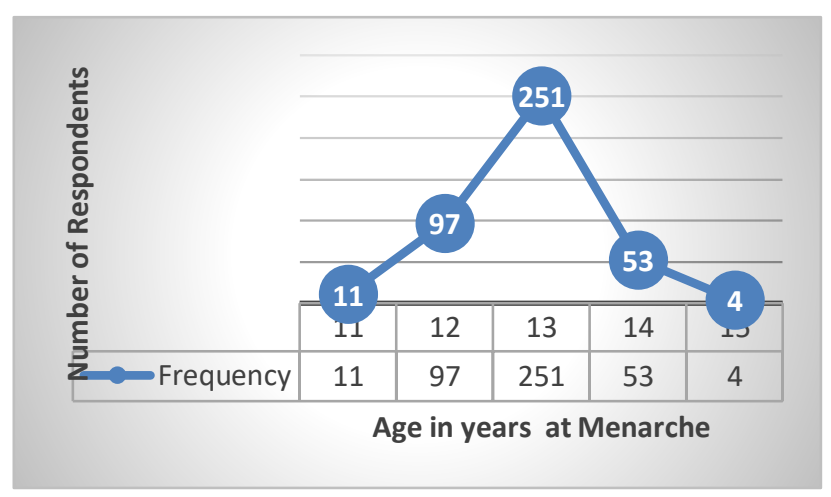

Figure 1: Age distribution at menarche.

Figure 1 is a display of the age at menarche of the respondents. The majority $251(60.3 \%)$ of the respondents had their first menstrual bleeding at 13 years of age followed by those at 12 years $97(23.3 \%)$. The mean age at menarche of the respondents was $12.9 \pm 0.7$ years and a range of 11-15years.

Table 2 shows the respondents knowledge about menstrual hygiene practices. Most $(77.9 \%)$ of the respondents learnt about menstruation and menstrual hygiene management premenarchal while the rest $(22.1 \%)$ learnt about it at menarche. The leading source of information to the respondents who were aware of menstrual hygiene prior to menarche were their immediate family female members $(82.2 \%)$ mostly the mothers $(68.8 \%)$. Only $9.9 \%$ and a meagre $0.3 \%$ learnt of 
menstrual hygiene from the teachers and health care providers respectively. About three of every five (56.3\%) of the respondents used absorbent sanitary pad for menstrual blood collection.

Table 2: Respondents knowledge about menstrual hygiene practices.

\begin{tabular}{|c|c|c|c|}
\hline Characteristics & Variables & Frequency & $\%$ \\
\hline \multirow{2}{*}{$\begin{array}{l}\text { Timing of } \\
\text { Awareness } \\
\text { n=416 }\end{array}$} & Premenarchal & 324 & 77.9 \\
\hline & Menarchal & 92 & 22.1 \\
\hline \multirow{4}{*}{$\begin{array}{l}\text { Main Source of } \\
\text { Premenarchal } \\
\text { Menstrual } \\
\text { Information } \\
\mathbf{n = 3 2 4}\end{array}$} & $\begin{array}{l}\text { Immediate } \\
\text { family } \\
\text { female } \\
\text { members }\end{array}$ & 266 & 82.1 \\
\hline & Teachers & 32 & 9.9 \\
\hline & Friends & 25 & 7.7 \\
\hline & $\begin{array}{l}\text { Healthcare } \\
\text { Providers }\end{array}$ & 1 & 0.3 \\
\hline \multirow{3}{*}{$\begin{array}{l}\text { Type of } \\
\text { Absorbent } \\
\text { Material } n=416\end{array}$} & Sanitary pad & 234 & 56.3 \\
\hline & $\begin{array}{l}\text { Toilet Tissue } \\
\text { Paper }\end{array}$ & 52 & 12.5 \\
\hline & Cloth & 130 & 31.2 \\
\hline
\end{tabular}

\$=Mother, elder sisters, grandmother etc

Table 3 shows the comparison of the respondents' choice of menstrual absorbent materials by their mothers' education. The respondents whose mothers had more than secondary school education were more than six folds more likely to use absorbent sanitary pad than their counterparts of less educated mothers. The observed difference was statistically significant ( $R R=6.3$, $\mathrm{p}<0.001)$. Furthermore, the subset of the respondents whose mothers were more educated almost $(0.7 \%$ vs. $47.8 \%$ ) did not use cloths. The observed difference again, was statistically significant $(\mathrm{RR}=0.02, \quad \mathrm{p}<0.001)$. Nonetheless, the subsets were similar in the use of toilet tissue paper for menstrual blood collection ( $p>0.05$ ).

Table 4 shows the respondents menstrual hygiene practices. Approximately four of every five (77.4\%) respondents changed their absorbent menstrual materials at the most twice daily during menstruation while the rest $22.6 \%$ change thrice or more. The same proportion had their bath at least twice daily during menstruation while one of five $(22.6 \%)$ bathed only once daily the same period. About one half $(50.2 \%)$ of the respondents used water and soap to wash the vulva and the perineal regions during menstruation while a little more than a quarter $(26.2 \%)$ used only water to wash. About three quarters of the respondents $(72.8 \%)$ washed front to back while over a quarter either washed back to front (23.6\%) or haphazardly(3.6\%).The majority $215(51.9 \%)$ disposed their menstrual materials by burning while over a quarter 108 ( $26.0 \%$ ) disposed in the refuse dump. Less than one half $(48.1 \%)$ of the respondents washed their hands before and after changing their menstrual blood absorbent materials. About one in ten of the respondents did not practice hand washing when changing the absorbent materials. The respondents who did not practice hand washing during change of menstrual materials either considered hand washing unnecessary $23(82.1 \%)$ or due to the lack of water and soap 5 (17.9\%).

Table 3: Maternal educational level by respondents choice of absorbent materials use ( $n=416)$.

\begin{tabular}{|c|c|c|c|c|c|}
\hline \multirow{2}{*}{ Characteristic } & \multirow{2}{*}{ Variables } & \multicolumn{2}{|c|}{ Maternal Education } & \multirow{2}{*}{$\mathbf{R R}(95 \% \mathbf{C I})$} & \multirow{2}{*}{ p-value } \\
\hline & & $>$ Secondary n (\%) & $\leq$ Secondary n $(\%)$ & & \\
\hline \multirow{4}{*}{$\begin{array}{l}\text { Absorbent } \\
\text { material }\end{array}$} & Sanitary Pad & $130(89.0)$ & $104(38.5)$ & $6.3(3.9-10.2)$ & $<0.0001$ \\
\hline & Cloth & $1(0.7)$ & $129(47.8)$ & $\begin{array}{l}0.02 \\
(0.0021-0.11)\end{array}$ & $<0.0001$ \\
\hline & Toilet tissue paper & $15(10.3)$ & $37(13.7)$ & $\begin{array}{l}0.80 \\
(0.51-1.26)\end{array}$ & 0.35 \\
\hline & Total & 270 & 146 & & \\
\hline
\end{tabular}

Table 4: Respondents menstrual hygiene practices.

\begin{tabular}{|llll|}
\hline Characteristics & Variables & Frequency & Percentage \\
\hline $\begin{array}{l}\text { Frequency of daily absorbent } \\
\text { change }\end{array}$ & $1-2$ & 322 & 77.4 \\
\cline { 2 - 4 } $\begin{array}{l}\text { Bathing pattern during } \\
\text { menstruation }\end{array}$ & $\geq 3$ & 94 & 22.6 \\
\hline \multirow{3}{*}{ Substance for washing } & $\geq 2$ & 94 & 22.6 \\
\cline { 2 - 4 } & Water only & 322 & 77.4 \\
\hline \multirow{2}{*}{$\begin{array}{l}\text { Direction of vulvo-perineal } \\
\text { washing }\end{array}$} & Water and soap & 109 & 26.2 \\
\hline Menstrual material disposal and antiseptic & Bront to back & 209 & 50.2 \\
\hline & Back to front & 98 & 23.6 \\
\cline { 2 - 4 } & Non specific & 303 & 72.8 \\
\hline
\end{tabular}




\begin{tabular}{|lllll|}
\hline Characteristics & Variables & Frequency & Percentage \\
\hline & Pit laterine & 64 & 15.4 \\
\cline { 2 - 4 } & Water closet & 28 & 6.7 \\
\cline { 2 - 4 } & Refuse dump & 108 & 26.0 \\
\hline \multirow{3}{*}{$\begin{array}{l}\text { Timing hand washing during } \\
\text { absorbent change }\end{array}$} & Before & 51 & 12.3 \\
\cline { 2 - 4 } & After & 137 & 32.9 \\
\cline { 2 - 4 } & Before and after & 200 & 48.1 \\
\cline { 2 - 4 } & NIL & 28 & 6.7 \\
\hline
\end{tabular}

Table 5: Menstrual challenges and interventions by respondents.

\begin{tabular}{|c|c|c|c|}
\hline Characteristics & Variables & Frequency & Percent \\
\hline \multirow{4}{*}{$\begin{array}{l}\text { Menstrual disturbances } \\
(n=416)\end{array}$} & Abdominal/waist pain & 157 & 37.7 \\
\hline & Malaise & 77 & 18.5 \\
\hline & Lack of concentration & 16 & 3.8 \\
\hline & Nil & 166 & 39.9 \\
\hline \multirow{4}{*}{ Interventions $(\mathrm{n}=\mathbf{2 5 0}$} & Medication from patent medicine dealer & 118 & 47.2 \\
\hline & Consulted doctor & 16 & 6.4 \\
\hline & Received medication from parents & 10 & 4.0 \\
\hline & Nil & 106 & 42.4 \\
\hline \multirow{2}{*}{ School absenteeism $(n=416)$} & School absenteeism & 128 & 30.8 \\
\hline & Nil & 288 & 69.2 \\
\hline
\end{tabular}

Table 5 shows menstrual challenges and the interventions by the respondents. As many as $250(60.1 \%)$ of the respondents experienced one menstrual disturbance or another. Abdominal and waist pain was the most (37.7\%) cited disturbance by the respondents followed by feeling of malaise $(18.5 \%$ ) while $39.9 \%$ had no any form of menstrual disturbance. The largest proportion (47.2\%) of the respondents who had disturbances received medication from the patent medicine stores while many $(42.4 \%)$ did nothing. About three of ten $(30.8 \%)$ of the respondents were absent from school at least once because of menstruation. The reasons the respondents cited for absent from school during menstruation were severe abdominopelvic pain 97 (75.8\%), religious reasons and uncleanness $21(16.4 \%)$ and lack of good toilet facilities in school for changing menstrual materials 10 (7.8\%).

\section{DISCUSSION}

In our study, which consisted of adolescents mostly between the ages of 14 and 16 years; the mean age at menarche was 12.9 years. Garba et al in Kano, Nwankwo et al in Enugu and Akinwaare in Ibadan and Nayak in India also observed the similar age of menarche among girls, of between 11 and 13 years. ${ }^{15-18}$ Okafor- Terver et al in Katsina however reported the age of menarche in their study to range from 14 to 16 years. ${ }^{19}$ Differences in age at menarche has been shown to be related to socioeconomic factors.

We noted that premenarchal education on menstrual hygiene practices was received by up to $77.9 \%$ of the respondents. This figure was similar to $85.4 \%$ out of 400 adolescents reported by Aluko et al in Ile-Ife but much lower than the $92.2 \%$ and $93.7 \%$ reported by Garba et al in Kano and Akinwaare et al in Ibadan. ${ }^{15,17,20}$ The source of premenarchal information was mainly from immediate female family members which included mothers and sisters in up to $82.1 \%$ of cases and teachers in less than $10 \%$ of cases. This was at variance with what was reported by Garba et al where parent/guardians and school teachers were the main source of information in $62.0 \%$ and $19.0 \%$ of cases respectively. ${ }^{15}$ The lower percentage of girls who received premenarchal information in our study may be due to the lower educational levels of the mothers and possible poorer ability to communicate to their daughters. Also, slightly over half of the adolescents were the first females of the family and so may not have older female siblings to teach them. Ilo et al who conducted a study on 1191 adolescents in Abakiliki South Eastern Nigeria observed that those who had elder sisters had better knowledge of menstrual hygiene than their counterparts. ${ }^{21}$

Our study showed sanitary pads were the most used menstrual absorbent among the adolescents in $56.3 \%$ of cases. This figure was higher than the $32.7 \%$ reported by Adinma et al among 550 adolescents in Onitsha South East Nigeria. ${ }^{22}$ Garba et al reported that sanitary pads were the most used menstrual absorbent among the adolescents in $92.2 \%$ of cases. ${ }^{15}$ The lower rates of use of sanitary pads in our study could be due to the fact that it was in Umunna a semi urban area in Imo State with mothers of lower socioeconomic status than those in Kano metropolis.. Thus affordability could have played a major role in the number of adolescents using the sanitary pad. Oche et al in Sokoto found a significant association 
between the socioeconomic status of the mothers and the choice of menstrual absorbents the adolescents used. ${ }^{23} \mathrm{~A}$ study conducted in Pakistan by Rizvi et al also revealed that most school girls did not use sanitary pads due to the high cost compared to reusable cloths. ${ }^{24}$ The use of sanitary pads was also found to be significantly higher in those whose mothers were of a higher level of education The association between use of sanitary pads and higher maternal educational status have similarly been described by other authors. ${ }^{17,21}$ In a survey of 828 adolescents in Western Ethiopia, Upasha et al reported that girls whose mother's education status was secondary school and above were $50 \%$ more likely to have good knowledge about menstruation and menstrual hygiene than their counterparts. ${ }^{25}$

This study showed that $77.4 \%$ of the respondents changed their menstrual garment once or twice a day, and bathed more than twice a day with soap and water. We also noted that about $50 \%$ correctly washed their perineum from front to back and $48.1 \%$ washed their hands before and after changing their menstrual garment. These findings were similar to reports from other parts of Nigeria. ${ }^{15,21}$ This good level of menstrual hygiene in these adolescents could be as a result of the premenarchal training which was obtained in most of them. Aniebue at al and Garba et al found that good menstrual hygiene practices were higher among the adolescents who had premenarchal training compared to those who did not. ${ }^{15,26}$

Among the methods of disposal of menstrual absorbent, burning of the used menstrual absorbent was the method of disposal in $51 \%$ of cases followed by disposal in a refuse dump and a pit latrine in $26 \%$ and $15.4 \%$ of cases .Disposal by burning of the menstrual absorbent was similarly reported by Akinwaare et al where it was the commonest mode of disposal. ${ }^{17}$ This finding was in contrast to reports from Garba et al in Kano and Upashe et al in Ethiopia where disposal of the used menstrual garments in the dustbin was the most common method of disposal. ${ }^{15,25}$ The location of our study population in a rural community may be the reason for this due to unavailability of proper disposal systems. Incineration however is a safe method of disposal as it is ecofriendly and reduces air pollution, an advantage over other methods of disposal. However this has to be done at home as most schools have no incinerator to ensure proper disposal at school. Okafor-Trevor et al found that the presence of an enabling environment improves hygiene practices among adolescents. ${ }^{19}$

Abdominal and waist pain and discomfort were the commonest symptoms reported in our study. This was similar to the report by Adinma et al in the same South Eastern Nigeria. ${ }^{22}$ It is important to note that the presence of abdominal pain was also a major reason for school absenteeism in $30 \%$ of the adolescents. This figure is higher than the $13.1 \%$ reported by Femi-Agboola et al in Ibadan ${ }^{27}$ but much lower than the $61.7 \%$ of girls who miss school in a Ugandan study. ${ }^{28}$ Nwankwo et al in Enugu similarly reported severe abdominal pain as a major cause of school absenteeism among 495 adolescent females in their study with up to $16.4 \%$ having to consult a doctor for their symptoms. ${ }^{16}$ Abdominal pain usually occurs as part of the premenstrual-syndrome and is reported to be debilitating for many adolescents. Other reasons as similarly noted in our study, for school absenteeism included lack of water and adequate toilet facilities, sanitary pads, privacy and concentration. ${ }^{28-31}$

This study drew its strength from the scientifically determined sample size and prospective dataset. However, this data was self-reported behaviors known to be fraught with inaccuracies from distortion of information which in this study might have been from poor recall or youthful shyness in volunteer of personal and sensitive information. Again this was a multicenter rural community-based data which may be a fair representative and true reflection of the larger community. Nonetheless, cross sectional study design is fraught with the weakness in making causal inferences and behavior analysis.

\section{CONCLUSION}

Menstrual hygiene knowledge and practices among adolescent females is still inadequate. Though, sanitary pads are the most common menstrual garment used, cloths and tissue use was also employed. Disposal of used menstrual garment was mainly by burning. Premenarchal knowledge was obtained in most of them and mainly from the female family members though use of sanitary pads was associated with a higher maternal education.

\section{Recommendations}

Premenarchal training of the girls on menstrual hygiene practices is here proffered. Menstrual hygiene management should be included in schools curriculum under sex and adolescent health education programme with frequent retraining throughout secondary schools.

Funding: No funding sources

Conflict of interest: None declared

Ethical approval: The study was approved by the Institutional Ethics Committee

\section{REFERENCES}

1. WHO, UNICEF, JMP. Consultation on Draft Long List of Goal, Target and Indicator Options for Future Global Monitoring of Water, Sanitation and Hygiene 2012. Available from: http://www.rural-watersupply.net/en/resources/details/378.

2. Wilbur J, Torondel B, Hameed S, Mahon T, Kuper H. Systematic review of menstrual hygiene management requirements, its barriers and strategies 
for disabled people. PLoS ONE. 2019;14(2):e0210974.

3. Sahin M. Guest editorial: Tackling the stigma and gender marginalization related to menstruation via WASH in schools programmes. Waterlines. 2015;34(1):3-6.

4. UNICEF, University E. WASH in Schools Empowers Girls' Education-tools for assessing menstrual hygiene management in schools. 2013.

5. UN. Sustainable Development Goal 6: Ensure availability and sustainable management of water and sanitation for all 2015. Available from: https://sustainabledevelopment.un.org/sdg6.

6. Winkler I, Roaf V. Taking the bloody linen out of the closet: menstrual hygiene as a priority for achieving gender equality. Cardozo Journal of Law and Gender 2015.

7. Naeem K, Klawitter S, Aziz A. Learning, acting, and learning (LAL) research on schools' menstrual hygiene management (MHM): Pakistan. Waterlines. 2015;34(1):104-12.

8. McMahon SA, Winch PJ, Caruso BA, Obure AF, Ogutu EA, Ochari IA, et al. 'The girl with her period is the one to hang her head' Reflections on menstrual management among schoolgirls in rural Kenya. BMC international health and human rights. 2011;11(1):7

9. SHN ZASD. JR. Menstrual hygiene and sanitation practices among adolescent school going girls: a study from a South Indian town. Int J Community Med Public Health (London). 2015;(2):189-94.

10. Chinyama J, Chipungu J, Rudd C, Mwale M, Verstraete L, Sikamo C, et al Menstrual hygiene management in rural schools of Zambia: a descriptive study of knowledge, experiences and challenges faced by schoolgirls BMC Public Health 2019;19:16.

11. Eijk AMV, Sivakami M, Thakkar MB, Bauman A, Laserson KF, Coates $\mathrm{S}$, et al. Menstrual hygiene management among adolescent girls in India: a systematic review and meta-analysis. BMJ. 2016;6(3):e010290.

12. WHO, UNICEF. Progress on drinking water, sanitation and hygiene: 2017 update and SDG baselines. Geneva: 2017.

13. Morgan C, Bowling M, Bartram J, Kayser GL. Water, sanitation, and hygiene in schools: status and implications of low coverage in Ethiopia, Kenya, Mozambique, Rwanda, Uganda, and Zambia. Int J Hyg Environ Health. 2017; 220(6):950-9.

14. Cochran WG. Sampling techniques 3rd ed New York: John Wiley \& Sons; 1977.

15. Garba I, Rabiu A, Abubakar IS. Menstrual hygiene among adolescent school girls in Kano. Trop J Obstet Gynaecol. 2018; 35:153-7.

16. Nwankwo TO, Aniebue UU, Aniebue PN. Menstrual disorders in adolescent school girls in Enugu, Nigeria. J Pediatr Adolesc Gynecol. 2010;23(6):358-63.
17. Akinwaare MO, Akindele OM, Oluwatosin OA. Menstrual hygiene practices among adolescents in selected secondary schools around the University of Ibadan, Nigeria. Journal of Medicine and Biomedical Research. 2016;15(1):92-101.

18. Nayak S, Toppo NA, Tomar SP, Kasar PK. Tiwari R. A study on practices regarding menstrual hygiene among adolescent girls of urban areas of Jabalpur District. Int J Med Sci Public Health. 2016;5:2355-7.

19. Okafor-Terver IS, Chuemchit M. Knowledge, belief and practice of menstrual hygiene management among in-school adolescents in Katsina state, Nigeria. J Health Res. 2017;31(Suppl.2):S179-87.

20. Aluko OO, Oluya OM, Olaleye OA, Olajuyin AA, Olabintan TF, Oloruntoba-Oju OI Knowledge and menstrual hygiene practices among adolescents in senior secondary schools in Ile-Ife, South Western Nigeria.Journal of Water, Sanitation and Hygiene for Development. 2014;4(2):248.

21. Ilo CI, Nwimo IO, Onwunaka C. Menstrual Hygiene Practices and Sources of Menstrual Hygiene Information among Adolescent Secondary School Girls in Abakaliki Education Zone of Ebonyi State Journal of Education and Practice. 2016;7(31):88-95.

22. Adinma ED, Adinma JI. Perceptions and practices on menstruation amongst Nigerian secondary school girls. Afr J Reprod Health. 2008;12:74-83.

23. Oche MO, Umar AS, Gana GJ, Ango JT. Menstrual health: the unmet needs of adolescent girls in Sokoto Nigeria. Sci Res Essays. 2012;7:410-8.

24. Rizvi N, Ali TS. Misconceptions and Mismanagement of Menstruation among Adolescents Girls who do not attend School in Pakistan. J Asian Midwives. 2016;3(1):46-62.

25. Upashe SP, Tekelab T, Mekonnen J. Assessment of knowledge and practice of menstrual hygiene among high school girls in Western Ethiopia BMC Women's Health. 2015;15:84.

26. Aniebue UU, Aniebue PN, Nwankwo TO. The impact of premenarcheal training on menstrual practices and hygiene of Nigerian school girls. Pan Afr Med J. 2009;2:9.

27. Femi-Agboola DM, Sekoni OO, Goodman OO. Dysmenorrhea and its effect on school absenteeism and school activities among adolescents in selected secondary schools in Ibadan, Nigeria. Nig Med J. 2017;58: 143-8.

28. Boosey R, Prestwich G, Deave T. Menstrual hygiene management amongst schoolgirls in the Rukungiri district of Uganda and the impact on their education: a cross-sectional study. Pan Afr Med J. 2014;19:253.

29. Tegegne TK, Sisay MM. Menstrual hygiene management and school absenteeism among female adolescent students in Northeast Ethiopia. BMC Public Health. 2014;14:1118.

30. Grant MJ, Lloyd CB, Mensch BS. Menstruation and school absenteeism: evidence from rural Malawi. Comp Educ Rev. 2013;57:260-84. 
31. Mason L, Nyothach E, Alexander K, Odhiambo FO, Eleveld A, Vulule J et al. 'We keep it secrets no one should know' - a qualitative study to explore young schoolgirls attitudes and experiences with menstruation in rural western Kenya. PLoS One. 2013;8(11):e79132.
Cite this article as: Duru CO, Ikeanyi EM, Merenu I. Knowledge and practice of menstrual hygiene among adolescent school girls in Umunna, Imo State, Southeast Nigeria: implications for parents, healthcare providers and policy makers. Int J Reprod Contracept Obstet Gynecol 2021;10:458-65. 